\title{
Extending Impression Management Theory: The Need for Privacy vs. the Need to Express Information on Instant Messaging Apps
}

\author{
Tsfira Grebelsky-Lichtman ${ }^{1,2}$, Ziv Adato ${ }^{1}$, Shira Traeger $^{1}$ \\ ${ }^{1}$ Department of Communication at The Hebrew University of Jerusalem, Israel \\ ${ }^{2}$ Department of Education at the Ono Academic College, Israel \\ Correspondence: Tsfira Grebelsky-Lichtman, Department of Communication at The Hebrew University of Jerusalem, \\ Israel; Department of Education at the Ono Academic College, Israel.
}

Received: Apr. 13, 2020

doi:10.11114/smc.v8i1.4853
Accepted: May 10, $2020 \quad$ Online Published: May 13, 2020

URL: https://doi.org/10.11114/smc.v8i1.4853

\begin{abstract}
Impression management (IM) is a central assertion in interpersonal communication. There is increasing interest in exploring IM in new media. However, studies exploring IM in popular instant-messaging apps are lacking. Our main aims in the present study are to fill this gap and extend IM theory toward an innovative theoretical and analytical framework of computer-mediated communication (CMC). This study analyzed the popular instant-messaging app WhatsApp, the largest app for social chatting that has users all over the world.

We utilized a multi-variant design of quantitative and qualitative analysis, and conducted content analysis of WhatsApp profiles $(\mathrm{n}=546)$; an online survey of WhatsApp users $(\mathrm{n}=600)$; and in-depth interpersonal interviews $(\mathrm{n}=30)$. The findings demonstrate the structure, motivations, and communication functions of CMC IM. The proposed framework provides composite theoretical explanations, of psychological and sociological perspectives, for the IM's conflicting motivations: the need for privacy and the need to express information. Moreover, this study delineates the effect of gender and marital status on IM through instant-messaging app. The theoretical and analytical framework develops an impression construct that both reduces and increases information, which activates synchronous and asynchronous features of instant-messaging apps, which affects interpersonal communication.
\end{abstract}

Keywords: impression management, new media, content analysis, visual communication, gender, marital status

\section{Introduction}

Impression management is a key theme in interpersonal communication. In recent years, there is increasing interest in researching IM and how it is expressed in new media (Krämer \& Winter, 2008; Rosenberg \& Egbert, 2011). However, studies exploring IM in popular instant-messaging apps are inadequate. The present study contributes by expanding the IM theory toward an innovative theoretical and analytical framework of computer-mediated communication (CMC). The objective is to extend our understanding of the complex communication process of IM in CMC, which both reduces and increases information. This study contributes by explaining the motivations underlying the communication process and the challenges of IM construction through instant-messaging apps.

This study develops a multimodal communication approach that explores a wide range of textual, visual, and structural levels of IM. This approach contributes by delineating aspects that activate synchronous and asynchronous IM constructions derived from inner and social motivations, in the context of new media. The study establishes implications from the new media of the popular instant-messaging app WhatsApp, the world's largest social chatting app, which has users all over the world. The study is the first to delineate the effect of two focal social factors of gender and marital status on IM through WhatsApp, which enables individuals to regulate IM process by expressing and restricting information. Our theoretical argument is that the new media of the instant-messaging apps alters IM construction, which presents new challenges of control over the presented information, and affects interpersonal communication.

\section{Literature Review}

\subsection{Impression Management Theory}

Impression Management (IM) theory is a key component of interpersonal communication. IM theory explains the process by which individuals try to control and structure the impression they make on others (Leary \& Kowalski, 1990). 
The impression created in the eyes of others has an important effect on how others will treat, and think about, the individual, as well as how the individual will behave and think about himself/herself and his/her self-perception (Feaster, 2010).

A central concept in IM theory is strategic self-presentation (Tidwell \& Walther, 2002), which involves a balance of sharing, restraining, and distorting information (Krämer \& Winter, 2008). Strategic self-presentation is propelled from the central motif of Gain as much as possible, and be punished as little as possible. The ultimate goal of strategic IM is idealizing the public self and presenting it in a positive, reliable manner. IM is most common in everyday life (DePaulo et al., 1996).

IM theory is explained by both sociological and a psychological perspectives. Underlying these two theoretical perspectives is the need to control the impression (Feaster, 2010; O'Sullivan, 2000).

The sociological perspective is based on the important concept of the term face, established by Goffman (1959), which is conceptualized as the social image that mirrors how a person wants to be perceived by others. Goffman (1959) emphasizes the importance of IM, which defines the role of the individual in society and the reaction of others, in accordance with this role. According to Goffman, when we communicate with others, we are on stage. Other researchers developed IM theory and strategic self-presentation as a means to influence how others think about the presenter's characteristics and composed elements of the social-role theory (Eagly, Wood \& Diekman, 2000). The main motif for self-presentation from the sociological perspective is social, or acting in front of an audience to influence their perceptions and behaviors (Baumeister \& Tice, 1986).

The psychological perspective explains IM based on the term self-monitoring, which is described as a personality characteristic that refers to an ability to regulate one's performance to correspond to various social situations. Individuals concerned with their expressive self-presentation (IM) carefully monitor and attune their behavior to guarantee suitable or desired public appearance (Jones et al., 1965). Self-monitors attempt to explain how individuals and groups will perceive social performance. Some personality types often act spontaneously (low self-monitors) and are more internally guided. Others tend to intentionally control and adjust their performance to create a favorable impression (high self-monitors). From the psychological perspective, IM and self-presentation examine one's ability to adjust and regulate the impression of personal qualities on others (Day \& Schleicher, 2009; Snyder \& Gangestad, 2000). The main motif for self-presentation from a psychological perspective is the creation of a public self-presentation of the ideal or desired self (Baumeister \& Tice, 1986).

IM is divided into two components: impression motivation and impression construction (Leary \& Kowalski, 1990). This study presents a comprehensive analysis of these two components. The first component requires effort, which encourages people to manage the impression they make on others. Motivation is strengthened by the likelihood that IM will achieve the desired goals. The more motivation is strengthened, the more people desire IM and the more there is an inconsistency between the existing public image and the image people want to have. The second component is impression construction (Leary \& Kowalski, 1990), which includes the strategies of managing an impression. Impression construction is influenced by a person's self-perception, as well as the presenter's qualities, values, social role, and desired social image. Consistency is a key element in constructing the impression because inconsistency is perceived as unreliability.

\subsection{Computer-Mediated Communication Impression Management}

Computer-mediated communication (CMC) includes various interpersonal communications that are accessed by personal computers and mobile devices, including instant-messaging apps such as WhatsApp (Beißwenger et al, 2014). Studies indicate a great ability to succeed at IM via CMC (Becker \& Stamp, 2005; Merkle \& Richardson, 2000). People who interact with CMC tend to send messages with more emotional content and are more likely to develop online relationships than those who don't (Walther, 2007). In addition, people who communicate via CMC are more confident in the impression they create and more prone toward strategic self-presentation (Tidwell \& Walther, 2002). CMC enables strategic self-presentation, which is idealized by the narrow format for presentation it allows (Walther, 1996). Walther suggests that CMC's hyper-personal model allows for strategic IM and better self-presentation than with face-to-face (FTF) communication. Time does not play a role, so both message senders and recipients can devote considerable thought to writing, deciphering, and answering (Feaster, 2010). Due to the characteristics of the media, which allows time to edit messages, and write them offline, individuals devote extra time and cognitive effort in editing their messages, especially when sending them to the opposite gender (Walther, 2007).

In relationships mediated by technology, the channel's role is critical (O'Hara et al, 2014). People tend to prefer channels through which less information can pass, due to their desire to preserve privacy and maintain better IM (O'Sullivan, 2000). This avoids self-disclosure of embarrassing or negative information, and increases control of shared information. Feaster (2010) presented the information-control scale as a media affordance that explains how the use of a medium 
intensifies or weakens an individual's capability to regulate or restrict the flow of information throughout social interactions. The information-control scale describes how CMC channels support the process of strategic self-presentation in relation to expressive information and the need to control privacy.

Media affordance has been theorized as the developing junctures between a channel's features and the qualities of the channel user that drive outcomes in mediated communication environments (Rabinowitz et al, 2004). Media affordance is a central assertion in managing the tension between the need for information expression and the need for privacy, in order to overcome face threats that arise during social interactions (Petronio, 2002). Therefore, individuals must be afforded the capability to address both needs so they can manage the inherent tension between them. The proffered theoretical and analytical framework (see Figure 1) shows that high media affordance of IM is a two-dimensional construct that contains expressive information control combined with privacy information control. Therefore, media affordance explains how communication channels support the process of managing strategic self-presentation.

Based on the IM theory of CMC and the presented theoretical and analytical framework, we advanced the IM process and outcome. Figure 1 shows that the process emerges from impression motivations contains the conflicting needs for expressive information and privacy. Impression motivations activate media affordance of impression construction to achieve the desired goals of strategic self-presentation. The more the motivations are strengthened, the more media affordance increases. Impression constructions involve strategies to increase information activated by the need for expressive information and strategies to reduce information activated by the need for privacy.

H1: There will be a positive correlation of high media affordance in managing impression of increasing information and reducing information, or low media affordance in all.

\subsection{The Effect of Gender on CMC Impression Management}

Online disclosure norms are governed by rules that are culturally and socially dictated. Therefore, an intriguing question refers to the effect of gender on IM via CMC of social chatting instant-messaging apps. According to the social-role theory (Eagly, Wood, \& Diekman, 2000), socially constructed gender roles are considered when activating positive impressions in order to achieve main goals of favorable self-image. Guadagno et al. (2011) recently provided support for gendered social roles in online environments. Women are characterized as more communal caregivers, while men are seen as more agentic providers. According to Rui and Stefanone (2013), different gender norms lead to different communication behaviors. The argument is that men come across as less sentimental and less emotionally expressive than do women (Dosmukhambetova \& Manstead, 2012). Generally, women share more information and self-disclose than men do on $\mathrm{CMC}$, although it makes them more vulnerable to criticism. In conclusion, gender stereotypes remain present even when the users select images that represent them (Cooley \& Reichart Smith, 2010).

In line with social-role theory and previous studies, we developed the following hypotheses regarding gender and CMC IM construction (H1a) and motivation (H1b):

H2a: Women will display greater media affordance in managing their impression, by both increasing information and restricting information, as compared to men.

H2b: Women's media affordance will be more motivated to manage their social impression and more influenced by the opinions of others, as compared to men.

\subsection{The Effect of Marital Status on CMC Impression Management}

People manage impressions in many situations with different people, including family members, co-workers, new acquaintances, and potential romantic partners (Buss, 1980). A situation in which a person shows a romantic interest in somebody else can motivate and encourage IM. The desire to present oneself to a potential partner in the most attractive way in order to gain affection, leads to strategic self-presentation. People will try to show their positive qualities (or at least those they perceive as positive and appealing) when they can gain something from the situation and impress the other person. Individuals strategically manage their impression when they're in the presence of attractive potential partners (Griskevicius et al., 2007). Becker and Stamp (2005) argued that the more people desire a relationship the more they tend to use CMC IM strategies. Research argues that CMC is preferred for managing romantic impressions (Merkle \& Richardson, 2000). Therefore, we assume that marital status will affect CMC IM construction (H2a) and motivation (H2b):

H3a: Singles will display the greatest media affordance in IM by both increasing and restricting information, as compared to users in relationships. Users who are in a relationship, but not married, will display the second greatest media affordance, and married users will show the least amount of media affordance.

H3b: Singles' motivation for media affordance will be more conscious of their IM and more influenced by the opinions of the opposite gender regarding their IM, as compared to users in relationships. 


\subsection{Impression management in the instant-messaging app WhatsApp}

Although there has been increasing research interest in IM in new media recently, studies examining IM in instant messaging apps are inadequate. The objectives of this study are to expand IM theory toward mapping a novel framework for CMC IM in the popular instant-messaging app WhatsApp. Our aim is to present broad theoretical perspectives of IM in instant-messaging apps and examine the motivations, communication functions, and impression construction when using WhatsApp.

Instant messaging apps are rising in popularity worldwide. WhatsApp has over 1 billion users globally making it the largest app for social chatting used these days. When Facebook obtained it for $\$ 19$ billion in 2014, WhatsApp expanded rapidly around the globe. Nowadays, instant-messaging apps are helpful for keeping in touch with family, friends, and colleagues. WhatsApp is an instant-messaging app that is reminiscent of traditional SMS messages. However, it has unique features that offer a variety of strategies for IM, such as a personal profile that includes a status line and a picture, as well as features that make it possible to know if a message reached the recipient's device, when the recipient was last online, and if the recipient read the message. In a study comparing WhatsApp to traditional SMS messages (Church \& Oliveira, 2013) researchers discovered a tendency to use WhatsApp for close social relationships and group conversations. It was also perceived as facilitating natural, social communication.

In terms of IM construction, WhatsApp greatly resembles other online social networks in its ability to display a profile picture (Strano, 2008). Social-network users put a great deal of thought into choosing this picture (Krämer \& Winter, 2008). A study of online dating found that people give much consideration to the photos they upload (Ellison, Heino \& Gibbs, 2006), as well as to their profile picture (Krämer \& Winter, 2008). A recent study showed that students devote considerable thought to their profile pictures on Facebook (Hum et al., 2011). In WhatsApp, the profile picture is usually one of the only aspects visible to those who are not contacts of the profile owner. Therefore, the profile picture serves as a first attempt at IM.

Another strategy of IM that WhatsApp shares with other online social networks is the status line, which contains messages that the writer posts on their profile. The status line on Facebook for example, is visible to anyone that the writer chooses. Researchers found that people actively manage their impression using their Facebook status (Barash et al., 2010). WhatsApp also has a status line for each user, but it changes less often, unlike the status lines that frequently change on other social networks (Nartey, 2013). To know when a friend has changed their status line, you need to go to their contact page. However, noticing the change requires remembering the initial status line (Beißwenger et al, 2014).

Another one of WhatsApp's unique IM strategies is the last-seen stamp, which doesn't exist in other social networks or SMS messages. People use traditional text messages for privacy (Church \& Oliveira, 2013). The last-seen stamp disrupts the option of waiting before responding. Since the other person knows if you were online after their message reaches your device, a delay in writing and editing the message is disrupted. Failure to respond immediately may be perceived as being ignored (Church \& Oliveira, 2013).

Furthermore, WhatsApp has another unique strategy of IM, known as blue ticks. The app not only shows you if your message reached the recipient's phone, but when they read that specific message. Two blue ticks on the message, along with a timestamp of the message will show up. These unique strategies of the blue ticks and the last-seen function challenge the time dimension of the hyper-personal CMC model (Walther, 2007) and users' ability to conduct strategic self-presentation in asynchronous communication.

The presented theoretical and analytical framework (see Figure 1) proffers that high media affordance of IM is accomplished by a complex bipolar combination of strategies that increase expressing information: the profile picture and the status line, accompanied by strategies that reduce and restrict information and removing the last seen stamp and eliminating the blue tics.

\section{Method}

\section{Participants}

This study recruited students from compulsory communication courses, who received course credits in exchange for participating in the study. The sample contained $49 \%$ males and 51\% females. The participants ranged in age from 18 to 46 years $(M=24.16 ; S D=3.82)$. In terms of marital status, the sample consisted of $39 \%$ singles, $29 \%$ in a relationship and 32\% married. 600 participants completed the online survey, of which $564(94 \%)$ provided their WhatsApp profiles for content analysis (because of privacy concerns) and 30 took part in the in-depth, interpersonal interviews. The sample of the in-depth interviews consisted of participants who were able to participate in a personal interview, which was sampled from the study's population. 


\subsection{Content Analysis}

We conducted a content analysis of WhatsApp profiles, based on multimodal, complex indices, which analyzed visual, textual, and structural aspects. The WhatsApp profiles were coded by four advanced-undergraduate, research assistants. It took approximately five hours to train each coder. Fifty-six WhatsApp profiles ( $10 \%$ of the final sample), which were not part of the final sample, were used for training and calculating inter-coder reliability. When establishing inter-coder reliability, disagreements between coders were resolved by clarifying, and then reapplying the coding index guidelines until the coding categories achieved reliability (as assessed by averaging Cohen's kappa values across the four coders).

\section{The visual aspect - An analysis of the profile picture}

This content analysis explored the profile picture, based on the complex index developed by Hum et al. (2011). This index measures media affordance in the profile picture. Operatively, media affordance in IM, via the profile picture, comprises four variables. The level of physical activity contained four options: completely physically active; moderately active; inactive; or no user shown in the profile picture (average $\mathrm{k}=.91$ ). The index for candidness consisted the options: candid, between candid and posed, or posed (average $\mathrm{k}=.90$ ). The index of appropriateness contained the options: inappropriate, moderate, and appropriate (average $\mathrm{k}=.88$ ). Finally, the subject index provided the options of alone, couple (two individuals, although not necessarily romantic in nature), or group (three or more individuals) (average $\mathrm{k}=.92$ ).

\section{The textual aspect - Analysis of the status line}

This content analysis explored the status line, based on a complex index that analyzed the textual aspects. Operationally, the index of media affordance in the status line consisted of four variables: status originality (an original status or a default status line) (average $\mathrm{k}=.89$ ), number of emoticons (average $\mathrm{k}=.93$ ), number of characters (average $\mathrm{k}=.94$ ) and finally, number of words (average $\mathrm{k}=.92$ ). It is important to note that the characters and words were counted in a user's original status line and did not display the default status line.

\section{The structural aspect-Analysis of the last-seen stamp and the blue ticks displayed}

This analysis explored strategies of IM of two features that are unique to WhatsApp: the last-seen stamp and the display of the blue ticks. The analysis referred to the structural aspect of the last-seen stamp, examining whether or not it was left or removed. Operationally, this is a dichotomous index, in which the last-seen stamp is displayed or eliminated (average $\mathrm{k}=.91$ ). Removing the stamp represents greater media affordance in IM compared to keeping the stamp visible (the default), which indicates less of media affordance in IM.

The analysis of the structural aspect of the blue ticks was also based on a dichotomous index, in which we explored whether the blue ticks were displayed or eliminated (average $\mathrm{k}=.92$ ). Not displaying the blue ticks represented a greater level of media affordance in IM, since the user must actively remove their visibility.

\subsection{Online Survey}

Participants were asked to access an online survey. After providing consent, they were asked to respond to items measuring aspects relating to perceptions of the possibility of managing impressions via the WhatsApp app, impression motivations (IM) and impression construction (IC) via the profile picture, the status line, the last-seen stamp and the blue ticks.

Fourteen items were listed as statements of impression motivations and constructions performed within WhatsApp. These items were uniquely developed for this study, and they are listed in Appendix 1. Each participant was asked to respond to the items on a 5 -point scale $(1=$ Strongly Disagree $-5=$ Strongly Agree). Four items were designed to measure impression construction (IC). Ten items were designed to expose impression motivations (IM). The impression motivation items were designed to measure inner and social motivations for expressive information control, as well as motivations for privacy information control. In addition, the online survey contained demographic questions regarding gender and marital status (single/in a relationship/married).

\subsection{In-depth Personal Interviews}

In-depth personal interviews were conducted to provide a comprehensive understanding of IM constructions and their underlying motivations. We chose in-depth, face-to-face, personal interviews as the method of data collection to maximize in-depth understanding of the meaning of different attitudes and strategies. This allowed us to gain insights into perceptions and various motivations and reasoning for the communication process of IM. The in-depth personal interviews were semi-structured based on the themes in the online questionnaire (see Appendix 1). Each interview took approximately 40 minutes. 


\section{Results}

The findings supported $\mathrm{H} 1$ of the presented theoretical and analytical framework (Figure 1). Accordingly, high media affordance of increasing expressed information in the profile picture and the status line were positively correlated with a high media affordance of reducing information in removing the status line and eliminating the blue ticks.

In accordance of $\mathrm{H} 1$, the findings revealed a significant positive correlation between media affordance in the profile picture and in the status line $(\mathrm{r}=.321 ; p<.02)$. The study found that $45.5 \%$ of users who expressed media affordance in their status line also put the maximum amount of media affordance into their profile picture; $36.3 \%$ put in one level below the maximum amount; $11.1 \%$ put in one level above the minimal media affordance. Only $7.1 \%$ of those who expressed the most media affordance in their status line also put in the lowest level of media affordance in their profile picture. In addition, none of the users put maximum media affordance in the status line but did not have a profile picture. Of those who expressed minimal media affordance in the status line, $32.4 \%$ didn't have a profile picture, while $35.1 \%$ expressed maximum media affordance in the profile picture.

Moreover, in line with H1, a relationship was found between media affordance in the status line and removing the last-seen stamp. Of those who removed the last-seen stamp, $44.4 \%$ expressed the maximum level of media affordance in their status line, $11.1 \%$ expressed the second-highest level of media affordance in their status line, $35.6 \%$ expressed the second to lowest of media affordance, and $8.9 \%$ expressed the lowest level of media affordance in their status line. Of those who left the last-seen stamp visible, $6.1 \%$ expressed the highest level of media affordance in the status line, $31.3 \%$ expressed media affordance at the second-highest level, $29.3 \%$ expressed media affordance at the second to lowest level, and $33.3 \%$ expressed the lowest level of media affordance in their status line.

\subsection{Increasing Expressive Information: The Profile Picture}

The findings showed that the profile picture is perceived as the most effective means of IM in the WhatsApp app. Users manage their impression by using a high media affordance in the profile picture. Users invest time and effort in deciding which picture to display, and thinking how others will perceive the picture. "The picture is a kind of a window to how you see me. You can see much more than just how I look. It's what I present, whether serious or a silly joker, all sorts of things," A. said. "I want those who see the picture to think good things about me and get a positive impression." W. said. "It's important that the picture looks good." W. commented that the picture is "...supposed to represent me, who I am. I'm not going to take a picture especially for WhatsApp. I see a cool picture that represents me, and I say 'let's use it."' N. said, "It's important because the truth is that besides the picture, there's really nothing to see. I want to upload a picture that presents me the best way, yes, one that I look great in."

There are two main motivations for the profile picture: The first is creating a first impression, with the possibility of having a deep conversation or meeting. A picture should appeal to the person you are trying to impress. J. said, "If I just met someone, I could change the picture just because we met, and because I think this is the picture that will broadcast what I want to in the best way." A. mentioned she would choose a picture based on the effect she wanted to make on someone. "They should think that I have good eyes, cute." She also noted that the purpose of the picture is "to influence new people; less about those who already know me." The second motivation is for the picture to attract the attention of someone from the user's past, with whom they are no longer in touch, such as an ex-partner. O. said, "I changed my picture just to attract the attention of my ex, or a guy I went out with who disappeared." The picture actually serves as a means to provoke the spouse who left, supposedly making them think and wonder about what they lost.

\subsection{Increasing Expressive Information - The Status Line}

High IM is characterized by high media affordance in the status line, which includes originality and a high number of emoticons. However, the findings showed that using the status line for IM is perceived as one of the least important strategies. $56.9 \%$ of the users use the default status or template status. Moreover, $53.5 \%$ of the respondents' statuses were the default, and another $12.7 \%$ reported that their status was a template. The status line was treated as unnecessary and something to which users don't pay much attention. In some cases, they even mock it, as P. explained, "Sometimes I stumble upon statuses and think they are really dumb, and then I think to myself, why the heck did he write this dumb stuff?" D. stated, "My status is the default, I haven't changed it. I don't think anyone really cares what happens with it." However, users who placed significance on the status line highlighted the importance of originality. N. said, "I didn't want it broadcast that I was boring and lame."

\subsection{Reducing Information - The Last-Seen Stamp}

The findings showed that removing the last-seen stamp is second in perceived importance for IM, after the profile picture. People are aware of the possibility of managing impressions by using this strategy. Three main impression motivations derived from using the last-seen stamp. The first was removing the last-seen stamp to refrain from presenting a negative image. Users testified that they avoided connecting to the app so that other users would not think 
they were ignoring them. In doing so, they distanced themselves from a negative image of someone who filters messages on the app. Some interviewees said there were situations in which they refrained from connecting until they could answer messages or answered them because there was no choice. M. said, "If it's someone I'm really trying to avoid, I'll most likely leave the message unchecked until I want to answer. Or I'll just answer even if I don't feel like it, just because I don't feel comfortable since I know he saw it."

The second distinct motivation in turning off the last-seen stamp is to allow privacy and more time to think about how to respond. The purpose is to regain control over managing the impression and establish a dimension of mystery. More than $25 \%$ of the respondents said they removed the last-seen stamp because they didn't want others to see when they were connected. During the interviews, N. said, "I want privacy. I would go crazy if people could see when I was connected and whether I read the message or not. Sometimes I want time to think about the answer and not be limited in time." A. noted, "If I have the last-seen stamp in front of my eyes, I can go crazy." A. mentioned another reason why the last-seen stamp could be removed, other than to keep the mystery and control the dimension of time: sometimes the stamp is removed to protect against information that might harm the user.

However, this study exposes another motivation related to activating the last-seen stamp. If somebody else can see when the user is connected, it gives the impression that the user is popular or busy. This strategy is opposite to the previous motivations. Rather than using an image of someone that ignores or filters out other users, it actually uses that image to make other users wonder why they're being ignored after sending a message. Almost $22 \%$ of survey respondents indicated that it was important that other users see when they were last connected, and $31.7 \%$ stated that they sometimes waited before answering messages after reading them. For example, A. stated, "There were times when I saw a message I simply didn't want to answer, and let them get annoyed by seeing that I got the message, but I ignored it."

\subsection{Reducing Information - The Blue Ticks}

The blue-ticks strategy was perceived as less important than the last-seen stamp. The meaning of the two blue tick indicates that the recipient has read the message. Users said that this strategy could cause concern as to why the recipient is taking so long to reply to the message after having read it. The finding showed that users tested many friendships and relationships by WhatsApp's infamous blue-ticks. Therefore, this study found that the motivation of removing the blue ticks was to enable users to gain control over managing impressions, in terms of when to answer the message and its content.

\subsection{Perceptions of Importance and IM Construction}

The findings indicated a hierarchy in perceived importance of the various means of IM. This perceived importance influences the degree of media affordance, in terms of which IM strategy to use. Accordingly, the profile picture was perceived as having the greatest impact, so it had the greatest amount of media affordance. The last-seen stamp had the second-greatest amount of media affordance, followed by the blue ticks. The status line had the least amount of media affordance for managing impression. Furthermore, the need to control information was the primary motivation for media affordances among the various strategies of IM.

\subsection{The Effect of Gender on Impression Management}

Contrary to hypothesis $\mathrm{H} 2 \mathrm{a}$, the study revealed no significant difference between men and women in terms of the degree of media affordance in various IM strategies. However, in accordance with $\mathrm{H} 2 \mathrm{~b}$, significant gender differences were found in the motivations for using these strategies to construct impressions. Women particularly expressed more social-motivation for IM, while men expressed more inner motivations. Gender differences were also found in the explanations of why users created impressions and the degree of importance placed on various aspects of IM in the WhatsApp app.

Specifically, women $(M=2.93, S D=0.51)$ indicated that they avoided connecting to WhatsApp significantly more often than did men $(M=1.80, S D=0.72)$, so that other users wouldn't think that they read their messages and ignored them, expressing significantly more social motivations for media affordance than men $(t(599)=2.843 ; p<.01)$. More than $32 \%$ of the women said that they sometimes refrained from connecting to WhatsApp after receiving a message, so that other users won't think they read messages and ignored them, while only $13.6 \%$ of the men said this. Furthermore, $33.9 \%$ of the men reported that this motivation was wrong, while only $15 \%$ of the women said this. This relationship was significant $(\chi 2(5)=13.23$; Cramer's $\mathrm{V}=.31 ; p<.02)$.

There were significant gender differences regarding the statement: "It's important to me that my profile picture will present me in a positive light." $46.2 \%$ of the women stated that they strongly agreed with this statement, while $23.7 \%$ of the men strongly agreed with it. Furthermore, almost $24 \%$ of the women agreed with this statement, while only $16.9 \%$ of the men agreed. This relationship was significant $(\chi 2(5)=13.94$; Cramer's V $=.31 ; p<.01)$. 
Significant gender differences were also found regarding the statement: "I think about what the opposite gender will think when choosing my profile picture on WhatsApp." A total of $7.5 \%$ of the women said they gave it much thought, while $3.4 \%$ of the men said so. Another $7.5 \%$ of the women said that they gave it some thought, and $10.2 \%$ of the men said this as well. $31.2 \%$ of the women said that they didn't give any thought to it, as opposed to $52.5 \%$ of the men. This relationship was significant $(\chi 2(5)=12.49$; Cramer's $\mathrm{V}=.30 ; p<.01)$.

Women $(M=3.74, S D=0.91)$ also stated significantly more often than did men $(M=2.73, S D=0.86)$ that it was important for them to look attractive in their profile picture $(t(599)=4.20 ; p<.001)$. More than $22.5 \%$ of the women strongly agreed with the statement: "It's important for me to look attractive in my profile picture," while only $13.6 \%$ of the men strongly agreed with the statement. $21.2 \%$ of the women, but only $8.5 \%$ of the men, agreed with this statement, while $13.8 \%$ of the women and $44.1 \%$ of the men disagreed with this statement. This relationship was significant $(\chi 2(5)$ $=21.98 ;$ Cramer's $\mathrm{V}=.40 ; p<.0001)$.

Interestingly, a significant effect was found between gender and the number of times the user changed profile pictures $(\chi 2(5)=17.23$; Cramer's $V=.32 ; p<.01) .73 .1 \%$ of men hadn't changed their profile picture during the previous six months, compared to $29.7 \%$ of women. $19.2 \%$ of the men changed their picture once in the previous six months compared to $37.8 \%$ of the women. None of the men reported changing their picture twice in the previous six months compared to $13.5 \%$ of the women. $3.8 \%$ of the men changed their picture three times, while $10.8 \%$ percent of the women did so. None of the men changed their picture four times compared to $5.4 \%$ of the women. Finally, $2.8 \%$ of the men changed their picture five times in the previous six months compared to $3.7 \%$ of the women.

\subsection{The Effect of Marital Status on Impression Management}

In accordance with H3a, the findings showed that media affordance in IM was highly correlated with marital status. Single people put more media affordance into IM compared to those in relationships. Singles perceived their profile, and the various features that WhatsApp provides, as an additional platform to create an impression for romantic relationships. This effect was revealed regarding the importance of looking attractive in the profile picture, which was significantly more important for singles $(M=3.89, S D=0.65)$ than for those who were either in a continuous relationship or married $(M=2.38, S D=0.54),(t(599)=2.01 ; p<.05)$. In addition, singles $(M=4.56, S D=0.73)$ gave significantly more thought to what the opposite gender would think when choosing their profile picture compared to those in a relationship $(M=3.01, S D=0.58)(t(599)=2.231 ; p<.05)$.

However, in contrast to hypothesis H3a, married users invested more media affordance in IM than did those in long-term relationships. In examining the motivations of $\mathrm{H} 2 \mathrm{~b}$, relationship between marital status and consideration of the opposite gender regarding the profile picture, a significant effect was revealed $\left(\chi^{2}(5)=17.12\right.$; Cramer's $\mathrm{V}=.32 ; p$ $<.01$ ). $7.9 \%$ of the singles devoted a lot of thought to their profile picture, while $2.6 \%$ of interviewees in continuous relationships and $5.8 \%$ of those who were married gave it much thought. Conversely, $9.5 \%$ of the singles gave their profile picture little thought, while $2.6 \%$ of respondents in continuous relationships, and $13.5 \%$ of those who were married did so.

\section{Discussion}

This study expands IM theory by presenting an innovative theoretical and analytical framework for IM in the new media of the instant-messaging app WhatsApp. We established that WhatsApp brings new, broad strategies for IM, which alter and present new challenges for managing impression. The study defines unique strategies that both increase and reduce information. The high correlation between various strategies highlights the importance of consistency in IM. Furthermore, the study analyzes impression construction, which is explained through broad theoretical accounts, including psychological and sociological perspectives. Using the novel findings, this study develops a set of conclusions for an advanced theoretical and analytical framework of CMC IM.

\subsection{Impression Management's Primary Motivation is the Need for Control}

The theoretical and practical implications of the current study indicate that both increasing and reducing information serve similar motivations of maximizing control of CMC IM. This study develops Feaster's (2010) model, based on the information-control scale as a main base for IM. The study explains the unique practice of strategies to both increase and decrease information as a result of motivation for maximum control of constructing the impression. The need for control influences not only the choice of strategies for IM, but also the importance attributed to each strategy.

We concluded that WhatsApp increases the user's level of control over the information they present. Therefore, the app alters IM and allows for managing the preferred strategic self-presentation. This conclusion expands the hyper-personal model (Walther, 1996), which argues that CMC enables novel strategies of IM and better self-presentation, rather than FTF communication. 


\subsection{Dual Concerns of Self-Disclosure Affect CMC Impression Management}

This study advances a dual-concern effect of self-disclosure on CMC IM. Self-disclosure is conceptualized as the process of communication whereby one person reveals information about themselves to another person (Bazarova \& Choi, 2014). The different uses of CMC can affect the level of self-disclosure (O'Sullivan, 2000). WhatsApp activates dual concerns of self-disclosure, which affect IM. On the one hand, it provides IM strategies that increase information, which increases self-disclosure. The profile picture exposes personal details, so activates self-disclosure. This supports the argument of previous studies that CMC enables more self-disclosure compared to FCF communication (Becker \& Stamp, 2005; Beißwenger et al., 2014; Walther, 2007). On the other hand, WhatsApp enables strategic self-presentation that reduces information, which decreases self-disclosure. The app also promotes strategies that block information, such as removing the last-seen stamp and the blue ticks. These strategies express a need for less self-disclosure. The lower levels of self-disclosure are linked to the time lapse available when removing the option of the last-seen stamp or the blue ticks. This strengthens studies that argue for the importance of investing the time that is gained from the time lapse into thinking about a response that affects IM (Walther, 2007).

\subsection{Impression Management has a Psychological Inner-Motivation of Self-Monitoring}

This study explains that IM stems from self-monitoring psychological motivations. The WhatsApp app affects people's ability to influence the impression that their personal qualities leave on others, which confirms previous studies (Day \& Schleicher, 2009; Snyder \& Gangestad, 2000). However, this study extends the psychological inner motivations of self-monitoring to the theoretical and practical implications of CMC IM. We can conclude that the individual's social sensitivity and the level of fear of social judgment, or social evaluation, affect self-monitoring and influence the level of investment in strategic self-presentation. Individual self-perception is also affected (Feaster, 2010).

\subsection{Impression Management has a Social Motivation of Promoting Social Image}

The current study expands IM theory and strategic self-presentation as a means to influence how others think about the user's characteristics and composed elements of social-role theory (Eagly, Wood \& Diekman, 2000). From the sociological perspective, the main motif for self-presentation is promoting the individual's social image to act in front of an audience and influence its perceptions and behavior (Baumeister \& Tice, 1986; Rosenberg \& Egbert, 2011). Moreover, this motif affects CMC impression construction, specifically the construction of the user's face and social image.

\subsection{Asynchronous Communication Activates Strategies that Increase Information}

WhatsApp provides asynchronous communication, which activates strategies that increase expressive information. In particular, the profile picture and the status line represent asynchronous strategies that people use when carefully choosing the information they present (Strano, 2008; Krämer \& Winter, 2008). We can conclude that this new media of WhatsApp alters IM because it allows privacy and time to think about what information to present, due to the time lapse that the app offers (Walther, 2007). This motivation confirms Church and Oliveira's (2013) argument that users prefer asynchronous strategies, since time doesn't play a role. Moreover, this conclusion supports studies that indicate a high ability to succeed in IM through CMC enables asynchronous communication (Becker \& Stamp, 2005; Merkle \& Richardson, 2000).

\subsection{Synchronous Communication Activates Strategies that Reduce Information}

This study highlights the effect of synchronous communication, which leads to the preference of strategies that reduce information. In synchronous communication, many apps disable certain features (in default option) to create optimal IM and return control of the time dimension to the user. This argument confirms Church and Oliveira's (2013) findings that users felt that the last-seen stamp violated their privacy. The current study expands on this phenomenon and uniquely shows that high IM activated asynchronous strategies, in particular, use of both the last-seen stamp and the blue ticks. Online communication follows a separate, sometimes different, set of norms and rules (Young \& Quan-Haase, 2009). Specifically, removing these functions enables users to wait before responding, in order to decide to edit their response on the spot or postpone their answer if they can't answer at that moment. This allows for a time lapse in managing impressions (O'Hara et al, 2014; Walther, 2007). However, users who are not aware that these manipulations are available with these strategies, or who do not know how to change these options, face different challenges in achieving the IM that they aim for.

\subsection{Gender Affects CMC Impression Management}

Surprisingly, no gender differences were found in relation to constructing impressions and the degree of media affordance in managing them. This contradicts studies in the field (Guadagno et al., 2011; Rui \& Stefanone, 2013). However, this study discovered gender differences in motivations for using different impression constructions and the explanations for creating such impressions. This supports the social-construction theory of gender (Lorber, 1994), which 
argues that society and culture create gender roles, which are prescribed as ideal or appropriate behavior for a person of that gender. Furthermore, social conventions have a major effect on gender behavior (Schneider, Gruman \& Coutts, 2005). In particular, women are more likely than men to express social motivations and be concerned that other users not think they are being ignored. Therefore, women distance themselves from a negative image as someone who filters messages, as a main explanation for using strategies to reduce information. This confirms studies indicating that women try to present themselves as they would like to be seen by others, rather than as their real selves (Baumeister \& Tice, 1986; Dosmukhambetova \& Manstead, 2012).

\subsection{Marital Status Affects CMC Impression Management}

Marital status affects IM (Buss, 1980). In particular, romantic interest stimulates motivation and encourages high IM. The desire to present ourselves in the most attractive way to a potential partner, in order to gain affection, leads to strategic self-presentation. In line with previous studies (Becker \& Stamp, 2005; Griskevicius et al., 2007), this study confirms that the greater the desire for a relationship, the more people tend to use IM strategies on WhatsApp. Therefore, CMC IM is highly correlated with marital status. Single users put more media affordance into IM compared to those who are in relationships. Surprisingly, this study also uncovered that married people engage more media affordance in constructing their impression compared to their counterparts in long-term relationships without marriage. This trend expands social-role theory, which considers most of everyday activities to be acting out socially defined categories. Each role contains a set of rights, duties, expectations, and behaviors that a person faces and fulfills (Eagly, Wood \& Diekman, 2000). This study establishes that marital status predicts an individual's online conduct.

\subsection{Conclusions and Areas of Future Research}

In conclusion, this study contributes a theoretical and analytical framework of CMC IM and its implications in the new media of instant-messaging apps. New media brings novel, broad strategies for IM. However, it also presents new challenges, which alter IM and the level of control the individual has on the information presented. New media is an increasingly central tool in shaping the social image of an individual in modern society. Expanding IM theory through the instant-messaging app of WhatsApp reveals how this innovative technology enables users to advance, evolve, and find creative ways to effectively manage an impression and harness it for relevant personal purposes.

Future research may adopt the presented framework to explore the effect of various social and situational contexts, and delineate the effects of these contexts in activating CMC IM. This will further develop IM theory, and will enrich the theoretical and analytical framework into social and situational context approach to $\mathrm{CMC}$ and both impression motivations and construction.

\section{References}

Barash, V., Ducheneaut, N., Isaacs, E., \& Bellotti, V. (2010). Faceplant: Impression (mis) management in Facebook status updates. In: ICWSM. http://www.aaai.org/ocs/index.php/ICWSM/ICWSM10/paper/viewFile/1465/1858/

Baumeister, R. E., \& Tice, D. M. (1986). Four selves, two motives, and a substitute process self-regulation model. In: Public Self and Private Self(pp. 63-74). New York: Springer. https://doi.org/10.1007/978-1-4613-9564-5_3

Bazarova, N. N., \& Choi, Y. H. (2014). Self-disclosure in social media: Expending the functional approach to disclosure motivations and characteristics on social network sites. Journal of Communication, 64(4), 635-657. https://doi.org/10.1111/jcom.12106

Becker, J. A., \& Stamp, G. H. (2005). Impression management in chat rooms: A grounded theory model. Communication Studies, 56(3), 243-260. https://doi.org/10.1080/10510970500181264

Beißwenger, M., Oostdijk, N., Storrer, A., \& van den Heuvel, H. (2014). Journal for Language Technology and Computational Linguistics, 29(2). http://www.jlcl.org/2014_Heft2/Heft2-2014.pdf

Buss, A. H. (1980). Self-consciousness and social anxiety. Freeman.

Church, K., \& de Oliveira, R. (2013). What's up with WhatsApp? Comparing mobile instant messaging behaviors with traditional SMS. In: Proceedings of the 15th International Conference on Human-Computer Interaction with Mobile Devices and Services (pp. 352-361). ACM. https://doi.org/10.1145/2493190.2493225

Cooley, S. C., \& Reichart Smith, L. M. (2010). International Facebook faces: An analysis of self-inflicted face-ism in online profile pictures. Paper presented at the annual convention of the International Communication Association, Singapore.

Day, D., \& Schleicher, D. (2009). Self-monitoring. Encyclopedia of Positive Psychology, 19, 886-888.

DePaulo, B. M., Kashy, D. A., Kirkendol, S. E., et al. (1996). Lying in everyday life. Journal of Personality and Social Psychology, 70(5), 979. https://doi.org/10.1037/0022-3514.70.5.979 
Dosmukhambetova, D., \& Manstead, A. S. (2012). Fear attenuated and affection augmented: Male self-presentation in a romantic context. Journal of Nonverbal Behavior, 36(2), 135-147. https://doi.org/10.1007/s10919-011-0126-1

Eagly, A. H., Wood, W., \& Diekman, A. B. (2000). Social role theory of sex differences and similarities: A current appraisal. In: T. Eckes \& H. M. Trautner (Eds.), The Developmental Social Psychology of Gender (pp. 123-174). Mahwah, NJ: Erlbaum.

Ellison, N., Heino, R., \& Gibbs, J. (2006). Managing impressions online: Self-presentation processes in the online dating environment. Journal of Computer-Mediated Communication, 11(2), 415-441. https://doi.org/10.1111/j.1083-6101.2006.00020.x

Feaster, J. C. (2010). Expanding the impression management model of communication channels: An information control scale. Journal of Computer-Mediated Communication, 16(1), 115-138. https://doi.org/10.1111/j.1083-6101.2010.01535.x

Goffman, E. (1959). The presentation of self in everyday life. New York: Anchor. http://books.google.com/books?hl=en\&lr=\&id=TIIAzT5uT-

Griskevicius, V., Tybur, J. M., Sundie, J. M., Cialdini, R. B., Miller, G. F., \& Kenrick, D. T. (2007). Blatant benevolence and conspicuous consumption: When romantic motives elicit strategic costly signals. Journal of Personality and Social Psychology, 93(1), 85. https://doi.org/10.1037/0022-3514.93.1.85

Guadagno, R. E., Muscanell, N. L., Okdie, B. M., Burk, N. M., \& Ward, T. B. (2011). Even in virtual environments women shop and men build: A social role perspective on Second Life. Computers in Human Behavior, 27, 304-308. https://doi.org/10.1016/j.chb.2010.08.008

Hum, N. J., Chamberlin, P. E., Hambright, B. L., Portwood, A. C., Schat, A. C., \& Bevan, J. L. (2011). A picture is worth a thousand words: A content analysis of Facebook profile photographs. Computers in Human Behavior, 27(5), 1828-1833. https://doi.org/10.1016/j.chb.2011.04.003

Jones, E. E., Gergen, K. J., Gumpert, P., \& Thibaut, J. W. (1965). Some conditions affecting the use of ingratiation to influence performance evaluation. Journal of Personality and Social Psychology, 1(6), 613. https://doi.org/10.1037/h0022076

Krämer, N. C., \& Winter, S. (2008). Impression management 2.0: The relationship of self-esteem, extraversion, self-efficacy, and self-presentation within social networking sites. Journal of Media Psychology: Theories, Methods, and Applications, 20(3), 106. https://doi.org/10.1027/1864-1105.20.3.106

Leary, M. R., \& Kowalski, R. M. (1990). Impression management: A literature review and two-component model. Psychological Bulletin, 107(1), 34. https://doi.org/10.1037/0033-2909.107.1.34

Lorber, J. (1994). Night to his day: The social construction of gender. In: Paradoxes of Gender, (pp. 32-36). Yale University Press.

Merkle, E. R., \& Richardson, R. A. (2000). Digital dating and virtual relating: Conceptualizing computer mediated romantic relationships. Family Relations, 49(2), 187-192. https://doi.org/10.1111/j.1741-3729.2000.00187.x

Nartey, M. (2013). A speech act analysis of status updates on Facebook: The case of Ghanaian university students. Language in India, 13(12).

O’Hara, K. P., Massimi, M., Harper, R., Rubens, S., \& Morris, J. (2014). Everyday dwelling with WhatsApp. In: Proceedings of the 17th ACM Conference on Computer-Supported Cooperative Work \& Social Computing (pp. 1131-1143). ACM. https://doi.org/10.1145/2531602.2531679

O'Sullivan, P. B. (2000). What you don't know won't hurt me: IM functions of communication channels in relationships. Human Communication Research, 26(3), 403-431. https://doi.org/10.1111/j.1468-2958.2000.tb00763.x

Petronio, S. (2002). Boundaries of privacy: Dialectics of disclosure. Suny Press.

Rabinowitz, M., Blumberg, F. C., \& Everson, H. T. (2004). The design of instruction and evaluation: Affordances of using media and technology. Routledge. https://doi.org/10.4324/9781410611376

Rosenberg, J., \& Egbert, N. (2011). Online impression management: Personality traits and concerns for secondary goals as predictors of self-presentation tactics on Facebook. Journal of Computer-Mediated Communication, 17(1), 1-18. https://doi.org/10.1111/j.1083-6101.2011.01560.x

Rui, J., \& Stefanone, M. A. (2013). Strategic self-presentation online: A cross-cultural study. Computers in Human Behavior, 29(1), 110-118. https://doi.org/10.1016/j.chb.2012.07.022

Schneider, F. W., Gruman, J. A., \& Coutts, L. M. (Eds.). (2005). Applied social psychology: Understanding and 
addressing social and practical problems. Thousand Oaks, CA: Sage Publications.

Snyder, M., \& Gangestad, S. (2000). Self-monitoring: Appraisal and re-appraisal. Psychological Bulletin, 126(4), 530-555. https://doi.org/10.1037/0033-2909.126.4.530

Strano, M. M. (2008). User descriptions and interpretations of self-presentation through Facebook profile images. Cyberpsychology: Journal of Psychosocial Research on Cyberspace, 2(2), 5.

Tidwell, L. C., \& Walther, J. B. (2002). Computer-mediated communication effects on disclosure, impressions, and interpersonal evaluations: Getting to know one another one bit at a time. Human Communication Research, 28, 317-348. https://doi.org/10.1111/j.1468-2958.2002.tb00811.x

Walther, J. B. (1993). Impression development in computer-mediated interaction. Western Journal of Communication, 57, 381-398. https://doi.org/10.1080/10570319309374463

Walther, J. B. (1996). Computer-mediated communication impersonal, interpersonal, and hyperpersonal interaction. Communication Research, 23(1), 3-43. https://doi.org/10.1177/009365096023001001

Walther, J. B. (2007). Selective self-presentation in computer-mediated communication: Hyperpersonal dimensions of technology, language, and cognition. Computers in Human Behavior, 23(5), 2538-2557. https://doi.org/10.1016/j.chb.2006.05.002

Young, A. L., \& Quan-Haase, A. (2009, June). Information revelation and internet privacy concerns on social network sites: a case study of facebook. In Proceedings of the fourth international conference on Communities and technologies (pp. 265-274). https://doi.org/10.1145/1556460.1556499 


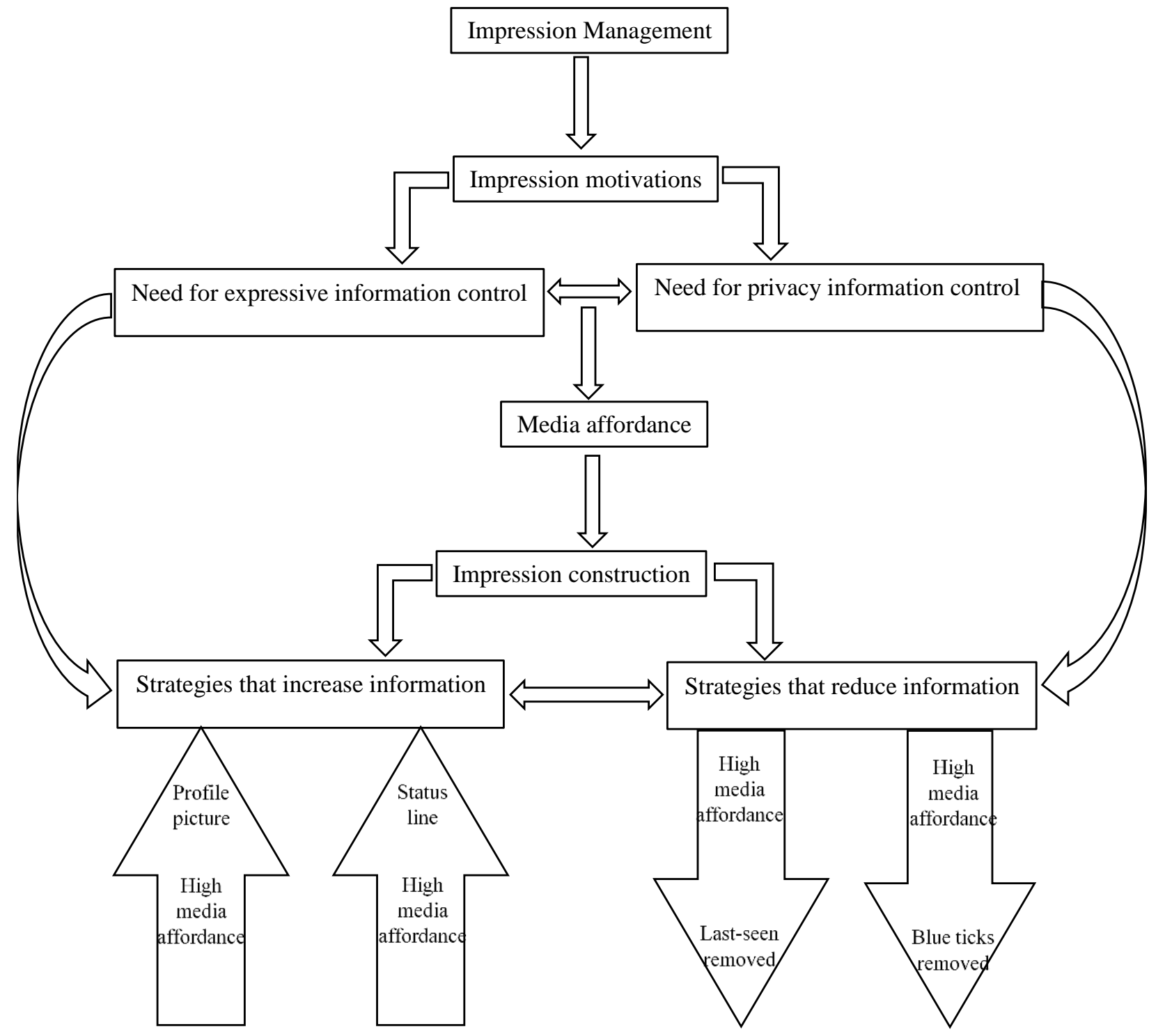

Figure 1. Theoretical and Analytical Framework of Impression Management in Computer-Mediated Communication (CMC) of WhatsApp Instant-Messaging App

*High impression management contains strategies that increase information, combined with strategies that reduce information 


\section{Appendix 1. Online Questionnaire}

For each of the following statements, please indicate how much you agree or disagree in relation to the instant-messaging application, WhatsApp. Five-point scales range from Strongly Disagree to Strongly Agree. Items refer to impression construction (IC) or to impression motivation (IM).

1. I give thought to what the opposite gender will think about my picture when choosing my profile picture on WhatsApp (IM).

2. I tend to change my profile picture often (IC).

3. I give thought to what the opposite gender will think about my status when typing a status on WhatsApp (IM).

4. It's important to me that my WhatsApp status will be original (IM).

5. I tend to change my status often (IC).

6. It's important to me that my profile picture will present me in a positive light (IM).

7. It's important for me to look attractive in my profile picture (IM).

8. It's important to me that my status will be witty (IM).

9. It's important to me that my status will be funny (IM).

10. I tend to turn off the blue ticks often (IC).

11. Sometimes I avoid connecting to WhatsApp, so others won't be able to see when I was last connected (IM).

12. Sometimes I avoid connecting to WhatsApp after receiving a message, so others won't think I read their message and ignored them.

13. I answer as fast as I can after reading a message, so others won't think I'm ignoring them (IM).

14. I often tend to eliminate the last-seen stamp (IC).

15. I sometimes wait before I answer after reading messages, so the other person will wait (IM).

\section{Copyrights}

Copyright for this article is retained by the author(s), with first publication rights granted to the journal.

This is an open-access article distributed under the terms and conditions of the Creative Commons Attribution license which permits unrestricted use, distribution, and reproduction in any medium, provided the original work is properly cited. 